OPEN ACCESS

Edited by:

Ulf Schmitz,

James Cook University, Australia

Reviewed by:

Khuloud Bajbouj,

University of Sharjah, United Arab

Emirates

Xin Lai,

University Hospital Erlangen, Germany

*Correspondence:

Constantinos M. Mikelis constantinos.mikelis@ttuhsc.edu

George Mattheolabakis

matthaiolampakis@ulm.edu

Specialty section:

This article was submitted to Pharmacology of Anti-Cancer Drugs,

a section of the journal

Frontiers in Oncology

Received: 05 May 2021 Accepted: 22 November 2021 Published: 09 December 2021

Citation: Lahooti B, Poudel S, Mikelis CM and Mattheolabakis G (2021) MiRNAs as Anti-Angiogenic Adjuvant Therapy in Cancer: Synopsis and Potential.

Front. Oncol. 11:705634. doi: 10.3389/fonc.2021.705634

\section{MiRNAs as Anti-Angiogenic Adjuvant Therapy in Cancer: Synopsis and Potential}

\author{
Behnaz Lahooti ${ }^{1}$, Sagun Poudel ${ }^{2}$, Constantinos M. Mikelis ${ }^{1,3 *}$ \\ and George Mattheolabakis ${ }^{2 *}$
}

${ }^{1}$ Department of Pharmaceutical Sciences, School of Pharmacy, Texas Tech University Health Sciences Center, Amarillo, TX, United States, 2 School of Basic Pharmaceutical and Toxicological Sciences, College of Pharmacy, University of Louisiana Monroe, Monroe, LA, United States, ${ }^{3}$ Department of Pharmacy, University of Patras, Patras, Greece

Angiogenesis is a key mechanism for tumor growth and metastasis and has been a therapeutic target for anti-cancer treatments. Intensive vascular growth is concomitant with the rapidly proliferating tumor cell population and tumor outgrowth. Current angiogenesis inhibitors targeting either one or a few pro-angiogenic factors or a range of downstream signaling molecules provide clinical benefit, but not without significant side effects. miRNAs are important post-transcriptional regulators of gene expression, and their dysregulation has been associated with tumor progression, metastasis, resistance, and the promotion of tumor-induced angiogenesis. In this mini-review, we provide a brief overview of the current anti-angiogenic approaches, their molecular targets, and side effects, as well as discuss existing literature on the role of miRNAs in angiogenesis. As we highlight specific miRNAs, based on their activity on endothelial or cancer cells, we discuss their potential for anti-angiogenic targeting in cancer as adjuvant therapy and the importance of angiogenesis being evaluated in such combinatorial approaches.

Keywords: angiogenesis, adjuvant therapy, miRNAs, drugs, combinatorial

\section{INTRODUCTION}

Angiogenesis is the physiological process for new blood vessel development from pre-existing ones. It is a highly coordinated, multistage process that occurs in physiological conditions, such as wound healing, the female reproductive cycle, and embryonic development, and many pathological conditions, including cancer. The angiogenic outcome highly depends on the balance of growth factors and angiogenesis inhibitors. Dysregulation of this balance leads to the increased or limited vascular network identified in a series of pathologies, such as retinopathies, inflammatory disorders, cardiovascular disorders, and tumors (1-3).

The rapid growth of tumor cells requires the continuous supply of oxygen and nutrients, the diffusion of which in vivo is significantly limited at 100-500 microns from the nearest capillary. Solid tumors cannot grow more than $2-3 \mathrm{~mm}$ in diameter and thus become dormant without vascular support $(4,5)$. The rapid proliferation of the tumor cells leads to their distant localization from the nearest capillary and the induction of hypoxia, a major driver of angiogenesis. Hypoxia leads to the secretion of many growth factors, such as vascular endothelial growth factor (VEGF) and basic fibroblast growth factor (bFGF), cytokines, such as interleukin 8 (IL-8), and other pro-angiogenic 
mediators, such as sphingosine-1 phosphate (S1P), leading to the proliferation, migration and tumor-like formation of the nearby endothelial cells (5-8). The newly formed tumor vessels are markedly distinct from the normal capillaries due to their chaotic structure characterized by the absence of proper orientation, the limited pericyte and smooth muscle cell coverage, blunt capillary ends, increased leakiness, and limited perfusion. The increased leakiness provides fertile ground for tumor cell dissemination and metastasis, while the limited mural support often leads to their collapse due to the higher interstitial pressure of the tumoral area, increasing further the hypoxic conditions $(3,5,9)$.

Targeting the tumor vascular network with anti-angiogenic therapy, despite the excellent preclinical results and the high potential these provided, did not meet the expectations in the clinic, with ephemeral results and not significant benefit in overall survival in most tumors. A prominent reason for this is considered the induction of compensatory mechanisms due to increased hypoxia upon anti-angiogenic treatment, which drives the overexpression of other pro-angiogenic factors, blocks immune functionality, and limits the perfusion of cytotoxic therapies $(10,11)$. During the last decade, the notion of vascular normalization as an outcome of anti-angiogenic therapy has risen, which can be achieved within a short therapeutic window during anti-angiogenic therapy. Tumor vascular normalization is expected to induce the integrity of the tumor vessels providing increased mural cell support, limited leakiness, inhibition of trans-endothelial cancer cell migration and metastatic incidence, and higher perfusion, which would limit the hypoxic areas and accommodate improved anti-cancer drug delivery in the tumoral area (12-14). The majority of the studies have focused on VEGF inhibition, the main target of antiangiogenic therapies. A precise dosage of VEGF inhibitors has been demonstrated to inhibit vascular permeability by tightening cell-to-cell contacts and recruiting pericytes. VEGF is not the sole mediator of vascular permeability, as an increasing volume of data has highlighted the involvement of other molecular players and pathways, such as Angiopoietin-2, Semaphorin 3A, nitric oxide, superoxide dismutase-3, Notch, WNT, platelet-derived growth factor-B (PDGF-B) and bone morphogenetic protein (MBP) signaling in this process $(10,11,13,15,16)$.

Nucleic acid-based therapeutics have attracted attention for the treatment of several diseases, including cancer $(17,18)$, inflammation (19), or the development of vaccines, such as against SARS-CoV-2 (i.e. COVID-19) (20-22). Among the different types of nucleic acids currently under research, miRNAs, natural molecules produced by the cells frequently transcribed along with protein-expressing genes $(23,24)$, are commonly dysregulated in diseases, such as cancer, inflammation, and others. Not surprisingly, miRNAs were recognized as potential prognostic and diagnostic markers in cancer (23-26). More importantly, as miRNAs are small, non-coding RNAs that utilize the cell's RNA interference mechanism to regulate multiple gene expressions, miRNAs are evaluated as therapeutic tools against cancer (23). An increasing body of literature focuses on dysregulated miRNAs for their properties as tumor suppressors or oncogenes, and on their action to either suppress or activate tumor-promoting pathways (23). Exogenous delivery of miRNA constructs, similarly to the exogenous delivery of siRNAs, aims to replace or correct observed miRNA dysregulations. Unlike siRNAs though, miRNA replacement therapies induce the expression or increase the levels of nucleic acid sequences naturally occurring in the cells, which should have an indistinguishable effect on the endogenous miRNAs $(23,24)$. Though this approach has limitations, the exogenous delivery of miRNAs should induce a strong beneficial effect on cells associated with the disease (i.e., cancer cells or cells of the tumor microenvironment with dysregulated miRNA expression) while having minimal effects on normal cells (i.e., absence of dysregulation) (27).

Representatively, miR-34a is characterized as a master tumor suppressor against multiple cancer types, capable of regulating proliferation, migration (28), apoptosis (29), metastasis, senescence, differentiation, and immune responses (30). Similarly, the clinical potential and translation of other miRNAs are currently undergoing. We are not outlining these studies, as several review publications focus on the current and past clinical trials [indicatively, refer to: (31-33)]. As miRNAs are expressed in all types of cells, miRNAs regulate vascular development and angiogenesis in endothelial cells (EC). Landskroner-Eiger et al. (34) summarized the importance of miRNAs in angiogenesis from the perspective of the Dicer enzyme. Dicer enzyme is a key component in the biogenesis of miRNAs, and several studies evaluated the effect of Dicer deletion/inactivation in normal vascular development. Dicer activity affected angiogenesis, attributed to defective miRNA expression, dysregulating the expression of VEGF and its receptors. As miRNA dysregulation in cancer has been well documented (35) either through cell-to-cell communication between cancer cells and EC or EC intracellular miRNA dysregulation, utilization of miRNAs as targets or regiments can benefit cancer treatments through regulation of EC function and formation of blood vessels $(36,37)$. There is an increasing interest in the combination of anti-angiogenic agents with traditional chemotherapeutics and several clinical trials pursued that approach $(2,38)$. We sought to explore the use of miRNAs for cancer treatment due to their ability to regulate angiogenesis and focus on their potential and utilization as adjuvant therapies with chemotherapeutics because of their anti-angiogenic properties. Although there is a substantial body of literature focusing on miRNAs and angiogenesis, limited work exists on their combination with chemotherapeutics predominately due to their anti-angiogenic properties. Here, we present miRNAs that are frequently studied due to their angiogenesis-inhibiting capacity and have been combined with traditional chemotherapeutics, even when the utilization of these miRNAs was not because of their anti-angiogenic properties.

\section{CURRENT ANTI-ANGIOGENIC THERAPIES}

Not long after its discovery, VEGF was characterized as a principal vascular regulator $(39,40)$. VEGF haploinsufficiency led to embryonic lethality due to impaired angiogenesis and 
blood vessel formation $(41,42)$. The striking impact on angiogenesis, vascular morphology, and functions upon VEGF inhibition or deficiency, along with its overexpression in most solid tumors, including lung, breast, liver, and ovarian cancers, brought it to the frontline of anti-angiogenic targets, where it remains till today. The first FDA-approved anti-angiogenic drug was bevacizumab, a monoclonal antibody against $\operatorname{VEGF}(43,44)$. Bevacizumab, combined with chemotherapy, improved overall survival in colorectal cancer (45) and soon provided encouraging results when tested in ovarian, cervical, non-small cell lung cancers, and mesothelioma. Today, bevacizumab is FDAapproved for colorectal cancer, non-small cell lung cancer, renal cell carcinoma, cervical, fallopian tube cancer, peritoneal cancer, and glioblastoma, whereas it failed to provide clinical benefit in the majority of the other cancer types, including breast cancer, for which the FDA approval lasted for a short period (2). Apart from bevacizumab, other antibody-based anti-angiogenic inhibitors are ramucirumab and aflibercept, which target VEGF receptor 2 (VEGFR2) or VEGF-A, VEGF-B and placental growth factor (PlGF), respectively. The rest of the angiogenesis inhibitors include small molecule or tyrosine kinase inhibitors that target one or more signaling pathways. Some of these tyrosine kinase inhibitors, such as sunitinib and regorafenib, inhibit a wide range of molecular targets and downstream mediators. The current, clinically administered anti-angiogenic inhibitors, their molecular targets, and the approved cancer types are presented below $(2,46-54)$ :

- Bevacizumab, targeting VEGF-A, for glioblastoma, colorectal, cervical, fallopian tube, peritoneal, non-small cell lung cancers and renal cell carcinoma.

- Ramucirumab, targeting VEGFR2, for gastric, gastroesophageal junction, non-small cell lung and colorectal cancers.

- Aflibercept, targeting VEGF-A,-B and PlGF, for colorectal cancer.

- Axitinib, targeting VEGFR1-3, for renal cell carcinoma.

- Cabozantinib, targeting VEGFR1-3, receptor tyrosine kinase (KIT), tropomyosin receptor kinase B (TRKB), anexelekto receptor tyrosine kinase (AXL), Rearranged during transfection (RET), tyrosine kinase MET, Fms-like tyrosine kinase-3 (FLT-3), TEK receptor tyrosine kinase (TIE2), for hepatocellular and renal cell carcinomas, and Medullary thyroid cancer.

- Everolimus, targeting mammalian target of rapamycin (mTOR), for breast, pancreatic, gastrointestinal, and lung cancers, Renal cell and subependymal giant cell carcinomas.

- Lenalidomide, targeting Ikaros family zinc finger protein 1,3 (IKZF1,3), E3 ubiquitin ligase, for follicular, mantle cell and marginal zone lymphomas, and multiple myeloma.

- Lenvatinib, targeting VEGFR1-3, for endometrial, hepatocellular and renal cell carcinomas and Thyroid cancer.

- Pazopanib, targeting VEGFR1-3, PDGF receptor- $\alpha / \beta$ $(\mathrm{PDGFR}-\alpha / \beta)$, fibroblast growth factor receptor 1,2 (FGFR1,2), c-KIT, for renal cell and soft tissue carcinomas.

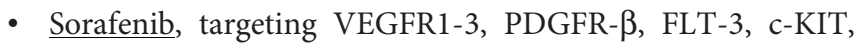
RAF kinases, for hepatocellular and renal cell carcinomas and thyroid cancer.

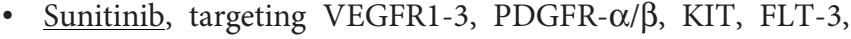
colony-stimulating factor receptor Type 1 (CSF-1R), RET, for gastrointestinal stromal and pancreatic cancers and renal cell carcinoma.

- Regorafenib, targeting VEGFR1-3, KIT, PDGFR- $\alpha / \beta$, FGFR1,2, TIE2, discoidin domain receptor tyrosine kinase 2 (DDR2), tropomyosin receptor kinase A (TRKA), Eph2A, RAF-1, BRAF, BRAFV600E, SAPK2, PTK5, Abelson tyrosine kinase $1(\mathrm{ABL})$, for gastrointestinal stromal and colorectal cancers and hepatocellular carcinoma.

- Thalidomide, targeting tumor necrosis factor- $\alpha$ (TNF- $\alpha$ ), for multiple myeloma.

- Vandetanib, targeting VEGFR, epidermal growth factor receptor (EGFR), RET, for medullary thyroid cancer.

\section{LIMITATIONS AND SIDE EFFECTS OF ANTI-ANGIOGENIC THERAPIES}

As seen above, most anti-angiogenic drugs are targeting VEGF or VEGFR, either solely or in combination with other growth factor receptors or downstream kinases. Their administration provides encouraging clinical benefit; however, their application is not without side effects. The two most critical side effects of antiangiogenic therapy are the induction of tumor aggressiveness along with metastatic potential and the tumor angiogenesis relapse due to the development of resistance mechanisms. The induction of tumor aggressiveness and metastatic potential upon anti-angiogenic therapy is still under debate, as it has been reported in preclinical models, but not always verified in other studies, demonstrating the variability of this phenomenon (55-57).

One of the limiting factors of anti-angiogenic therapy in cancer is that since cancer cells are not eradicated, as they do not consist the target of anti-angiogenic therapy, anti-angiogenic drugs have to be administered over long periods. The ephemeral outcome of anti-angiogenic therapy and the need for prolonged treatment eventually lead to the development of resistance upon anti-angiogenic inhibition. Resistance can be driven by the tumor cells, the stroma, immune cells, or endothelial progenitors, is mediated by the upregulation of alternative proangiogenic mediators, and presents cancer type- and patientspecific variability $(8,58)$.

Systemic anti-angiogenic drug administration, both in the case of antibody-specific VEGF inhibition and a wide range of tyrosine kinase inhibitors, can lead to organ- or tissue-specific side effects (59). A meta-analysis of five randomized clinical trials of metastatic colorectal, breast, and non-small cell lung cancers highlighted the risk of a thromboembolic event as another side effect of bevacizumab treatment in combination with chemotherapy (60). Cardiomyopathy and congestive heart failure have also been reported as side effects of antiangiogenic inhibitors (61). Although the exact mechanism for cardiomyopathy and congestive heart failure upon VEGF signaling blockade has not yet been fully delineated, the current notion is that existing conditions depleting the vascular 
reserve, such as hypertension and coronary artery disease, may be considered risk factors for cardiotoxicity with VEGF signaling inhibitors, while reduced nitric oxide production, mitochondrial dysfunction and pericyte population depletion have been attributed as potential mechanisms $(62,63)$. It has been further preclinically demonstrated that abrogation of the physiological VEGF activity can result in increased systemic (and coronary) vascular resistance and decreased cardiac output per se, which is the typical reason for cardiomyopathy development. Moreover, the roles of chemotherapy or radiation therapy as concomitant factors in VEGF blockade-induced cardiotoxicity have been further reported $(63,64)$.

Two well-known side effects of anti-angiogenic therapy that go hand in hand are the increased rate of hemorrhage and the inhibited wound healing process, both of which are determining factors for the timing of surgical procedures (65). Pulmonary hemorrhage with fatal outcome has been reported for non-small cell lung cancer patients with different anti-angiogenesis inhibitors, such as bevacizumab, ramucirumab, sunitinib, axitinib, and motesanib. A small percentage of gastrointestinal tumor patients developed bleeding at the tumor sites, while central nervous bleeding has also been reported $(61,65)$. Impaired wound healing is a common issue. Angiogenesis is a pivotal part of the wound healing process, mediated by VEGF and other growth factors, thus is expected that VEGF inhibition hampers the inflammatory and granulation wound healing phases, pivotal for the wound healing process. As an alternative, milder antiangiogenic treatments have been proposed to overcome this issue (66).To avoid wound healing deficiency of the surgical area anti-angiogenic treatment has to be terminated for at least four weeks before the surgical procedure so that the body will "wash out" the drug's effects $(61,65)$.

The above demonstrate the impact and role of angiogenic factors in physiological vascular functions, the interdependence of the primary tumor and the tumor microenvironment, the need for highly targeted, vascular-specific anti-angiogenic approaches, and the consideration of anti-angiogenic therapies specifically targeting aberrant angiogenesis, without affecting regular angiogenic functions.

\section{MiRNA THERAPEUTICS AND THEIR ADJUVANT POTENTIAL AGAINST ANGIOGENESIS}

As research on miRNAs rapidly proliferates, miRNAs' contribution in tumor suppression via anti-angiogenic function presented multifaceted therapeutic potentials for these molecules. miRNAs have primarily been studied for their activity as single molecules against cancer $(17,35,67)$. With numerous miRNAs being able to regulate cell functions and pathways, the number of potential mechanisms of action of miRNAs in angiogenesis correlates to the potential pathways associated with angiogenesis. Nonetheless, similarly to traditional anti-angiogenic approaches, studies on miRNAs and angiogenesis have primarily focused in known, more traditional angiogenic pathways. Thus, miRNAs studies focus on angiogenic factor receptors or signaling molecules in ECs to inhibit tumor angiogenesis (68), among them more prominently being VEGF, VEGFR and PDGFR (69-71). As numerous dysregulated miRNAs have been identified in tumor samples, here, we will present a few of the miRNAs with explicit action on angiogenesis and their identified molecular targets.

miR-34a, a master tumor suppressor, is one of the beststudied miRNAs, and, hence, its activity on tumor cells and cells of the tumor microenvironment has been thoroughly evaluated. Several studies have reported on miR-34a's ability to inhibit tumor angiogenesis. This activity takes place via multiple approaches, including the inhibition of the Silent Information Regulator 1 (Sirt1) expression, increase of the expression of acetylated Forkhead Box O1 (FoxO1) transcription factor, Notch 1 targeting, and the $p 53$ protein in endothelial progenitor cells and human cancer cells (72-75). miR-34a downregulation in EC induced BCL-2-overexpression and inhibition of apoptosis, while miR-34a upregulation suppresses tumor angiogenesis, EC proliferation, migration, and tube formation $(76,77)$. miR-34a has also extensively been studied in combination with several chemotherapeutics, such as cisplatin $(78,79)$, doxorubicin (80), sorafenib (81), and paclitaxel (82), among others. Despite the well-studied anti-angiogenic properties of the miRNA, we did not find research on its combination with a chemotherapeutic agent based solely due to its anti-angiogenic properties, rather than miR-34a's activity on the tumor cells.

Similarly, the miR-29 family, miR-29a, miR-29b, and miR-29c, are downregulated in various cancers, such as endometrial carcinoma, hepatocellular carcinoma, gastric cancer, and breast cancer (83-86). miR-29b overexpression inhibits angiogenesis and tumorigenesis in vivo and weakens tube formation, cell proliferation, and migration in vitro (83). miR-29b prevented tumor angiogenesis by targeting AKT3 and inhibited Akt3mediated VEGF and C-myc activations (86). In a gastric cancer mouse model, miR-29a/c prevented tumor growth, tube formation, and suppressed angiogenesis by suppressing VEGF-A expression (87). Similar to miR-34a, members of the miR-29 family have been attributed with tumor-suppressive properties and evaluated with several chemotherapeutic agents, such as cisplatin (88), and paclitaxel (89), among others. Of interest, miR-29a has been reported to contribute to doxorubicin resistance in breast cancer cells (90) and inhibit doxorubicin resistance in colon cancer cells (91). Li et al. (92) reported that cisplatin treatment induces upregulation of miR-29b, which suppressed invasion and angiogenesis of the cancer cells in vitro and inhibited tumor growth and neovascularization in vivo. The authors demonstrated that ectopic expression of miR-29b via intravenous administration in a subcutaneous xenograft mouse model of cervical cancer (HeLa cells) inhibited tumor growth and VEGF expression, corresponding to a decrease in vessel formation, although the authors did not evaluate this activity with the coadministration with cisplatin.

miR-221 and miR-222 modulated the angiogenic behavior of human umbilical vein endothelial cells (HUVECs) through the 
regulation of c-Kit expression (93). As these miRNAs were among the most abundantly expressed miRNAs in ECs (94), Nicoli et al. reported that miR-221 is essential for angiogenesis, in the zebrafish model (95). In human venous or lymphatic endothelial cells, miR221 has been shown to inhibit angiogenesis (93, 96-98). miR-221 has been identified as oncogenic in pancreatic cancer cells (99), glioblastoma (100), breast cancer (101), and lung cancer (102), among others. miR-221/222 have also been associated with increased chemoresistance to cisplatin in ovarian (103) and breast cancer cells (104). Similar results have been reported with Adriamycin (doxorubicin) (105, 106), 5-fluorouracil (107), and paclitaxel (108). Representatively, in vivo analysis of downregulation of miR-221/222 through local injection in a breast cancer mouse model enhanced the cisplatin's tumor growth inhibition capacity, but no analysis on tumor vasculature took place (104). In fact, in the in vivo studies of the miRNA-drug combinations, angiogenesis was not evaluated. This complex behavior is a representative example of the multi-faceted activity of miRNAs, which can be cancer- or cell-type-specific, and their combination with drugs can extend outside of the tumor cells, to the tumor microenvironment.

The expression of the most potent angiogenesis modulators in different tumors in terms of downstream targets of miRNAs has been extensively studied. Multiple miRNAs have been found to target VEGF since it is the most potent trigger for angiogenesis. miR-20 (109), miR-29b (110), miR-93 (111, 112), miR-126 (113, 114) target the 3 '-UTR region of VEGF-A mRNA. Following, we provide representative examples of miRNAs with antiangiogenic properties that also demonstrated anti-tumoral activity. miR-27b $(115,116)$ and miR-128 (69) suppress tumor progression and angiogenesis by targeting VEGF-C. miR-125b suppressed EC tube formation by inhibiting E-cadherin (117). miR-192 targets EGR1 and HOXB9, leading to anti-tumor and anti-angiogenic activity in human ovarian epithelial tumors (118). miR-200 family inhibited angiogenesis through direct and indirect mechanisms by targeting interleukin-8 (IL8) and CXCL1 secreted by the tumor endothelial and cancer cells (119). Overexpression of miR-190 inhibited EMT and angiogenesis by inactivating AKT-ERK signaling (120). miR-206 inhibited HGFinduced epithelial-mesenchymal transition (EMT) and angiogenesis in lung cancer, by suppressing Met/PI3k/Akt/ mTOR signaling (121). miR-135a promoted cell apoptosis and inhibited cell proliferation, migration, invasion, and tumor angiogenesis by targeting the IGF-1 gene through the IGF-1/ PI3K/Akt signaling pathway in non-small cell lung cancer (NSCLC) (122). Finally, miR-143 and miR-506, alone and in combination have been reported to affect angiogenesis, by inhibiting tube formation in HUVEC cells, while causing apoptosis to lung cancer cells (123).

As the VEGF family and its downregulation have been implicated in drug resistance in tumor cells (124-126), it is reasonable to predict that miRNAs with the capacity to target members of the VEGF family will become part of a cellsensitization goal for specific chemotherapeutics. Due to this reason alone, studies of miRNA-chemotherapeutic drugs combinatorial use for cancer treatment have the potential to proliferate in the future (Figure 1). One representative example would be miR-126, where Zhu et al., (127) demonstrated that miR-126 decreased the minimum inhibitory concentration of Adriamycin and Vincristine by targeting VEGF-A. In Table 1, we present a short list of studies with miRNAs with known antiangiogenic activity in combination with chemotherapeutics.

Illustratively, Wang et al. (155) studied the combination of miR-30a-5p with gefitinib to overcome drug resistance via regulation of the insulin-like growth factor receptor-1 (IGF1R) and hepatocyte growth factor receptor signaling pathways in NSCLC both in vitro and in vivo. Liang et al. (156) formulated exosomes to simultaneously deliver the anticancer drug 5-FU and a miR-21 inhibitor oligonucleotide (miR-21i) to 5-FUresistant colon cancer cells. This approach reversed drug resistance and significantly enhanced the drug's cytotoxicity in 5-FU-resistant colon cancer cells, compared to the single treatment with either miR-21i or 5-FU in an in vivo mouse model. Similarly. miR-375-3p, which has been reported to suppress tumorigenesis and reverse chemoresistance in colon cancer, along with 5-FU co-delivered in lipid-coated calcium carbonate nanoparticles were used to study the role of miR-375$3 \mathrm{p}$ in 5-FU-resistance in colorectal cancer $(157,158)$.

\section{DISCUSSION}

It is evident that miRNAs can have a significant impact on angiogenesis and cancer treatment. As our knowledge on miRNA activity expands, the highly complex interaction between miRNA and angiogenesis due to autocrine or paracrine interactions will dictate the future potential of the miRNAs as therapeutic tools. One major hurdle of anti-cancer therapies, including the anti-angiogenic therapies described above, is the off-target effects due to non-specific tissue- or cell-targeting. This hurdle is further exacerbated with the miRNAs, as the tumor type and the multifaceted activity of the miRNAs can have synergistic or antagonistic therapeutic outcomes through the tumor microenvironment. Thus, the in vivo evaluation of the miRNAs needs to expand outside the tumor cell growth and incorporate aspects, such as angiogenesis. Another parameter to be taken into account for miRNA-based therapies is the promiscuous binding of high miRNA dose, causing multiple off-target effects. This significant hurdle of miRNA-based treatments can be resolved by miRNA cooperativity and lower miRNA doses, while it is noteworthy that the final outcome of the targets of the cooperating genes strongly depends on the cellular environment (159).

miRNA delivery has been challenging by itself, due to the nucleic acids' rapid elimination from the circulation, the abundance of nucleases in vivo, and the need for a carrier for the large hydrophilic nucleic acid constructs to enter the cells (23, 24). The added complexity of the required cell type drug delivery specificity presents an additional challenge, which needs to be potentially overcome in the presence of an already impaired tumor vascular system (26). Several novel delivery carriers have been developed and studied for the delivery of miRNAs. These 
TABLE 1 | Representative examples of combinatorial miRNA-chemotherapeutics treatments.

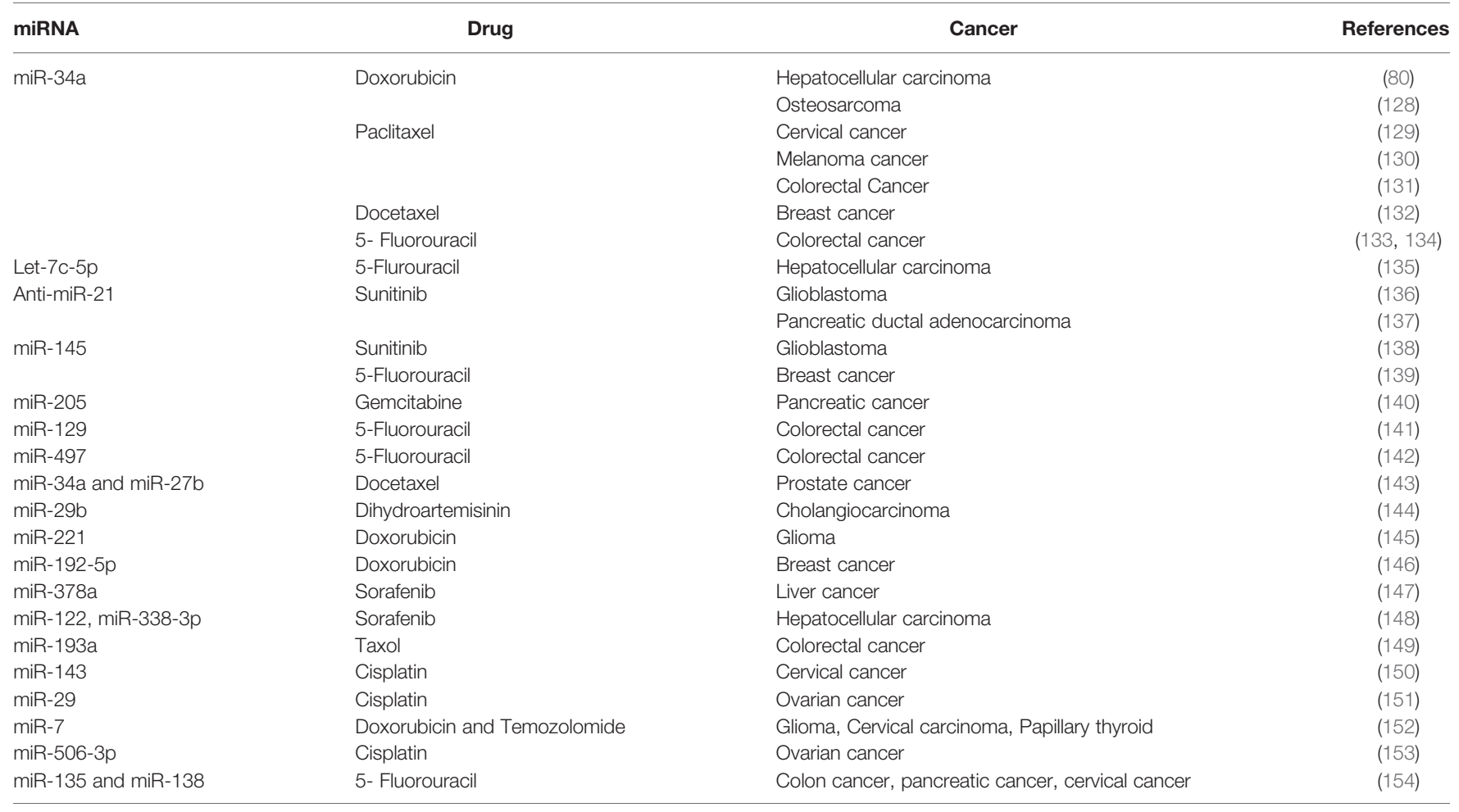

All miRNAs listed have tumor-inhibiting properties.

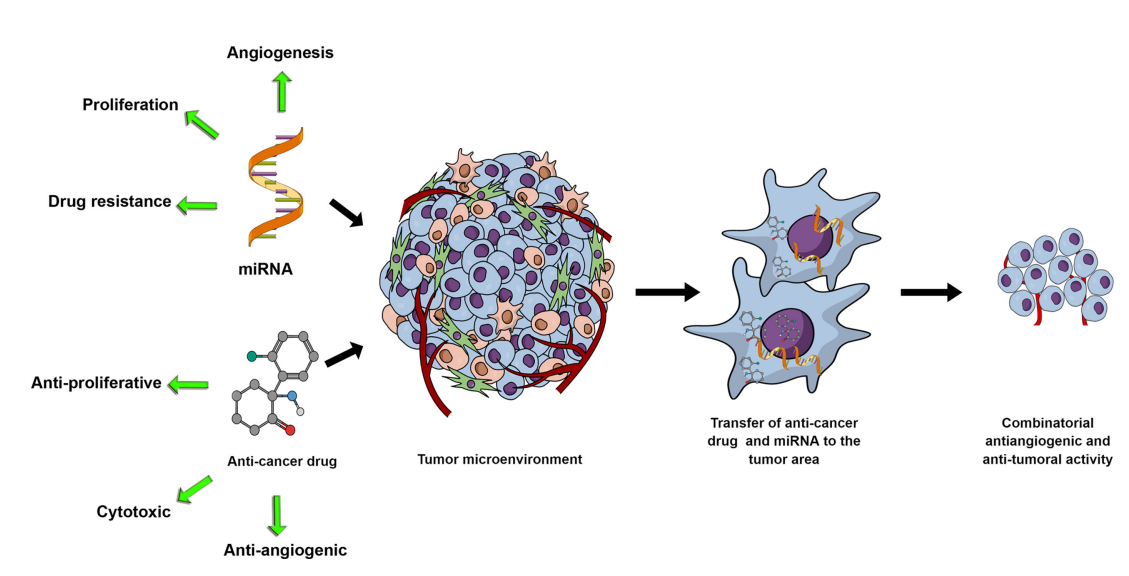

FIGURE 1 | miRNA and anti-cancer drug combinations can potentially synergistically affect tumor growth through their respective activities and potential synergistic effects on the tumor cells and the tumor microenvironment. With miRNAs mediating cell proliferation, drug resistance or angiogenesis, exogenous upregulation or inhibition of miRNAs in combination with anti-proliferative, cytotoxic or anti-angiogenic drugs represents a rationally designed and promising research development.

include micelles, polymeric nanocarriers, lipid-based carriers, viruses, inorganic carriers, and systems with long-circulating properties and/or active targeting to receptors over-expressed in cancer cells (23). Although the goal of a single organ and single-cell type targeting maybe be understandably impractical, these methodologies have provided significant benefits for minimizing off-target effects, increasing accumulation in the tumor, and preferentially increasing drug/nucleic acid concentration in specific cell types. Nonetheless, off-target effects will persist, even due to cell-to-cell communication.

This perspective has a significant impact when studying miRNA-drug combinations. Although in vitro analysis is fundamental to evaluate the synergistic/antagonistic behavior of a miRNA and a drug, the effect of the co-delivery of the miRNA-drug combination in vivo should take into consideration the anti-angiogenic properties of the miRNAs. Of course, this 
easily expands to other aspects of the tumor microenvironment, such as macrophages, though immunosuppressed animal models will present challenges for such evaluation.

Though we recognize that there might be published research on miRNA-drug combination focusing on angiogenesis we overlooked, it is apparent from our analysis that currently the anti-angiogenic aspect of miRNAs co-delivered with drugs is not the primary focus, or is not studied in detail or at all, even for miRNAs with known anti-angiogenic properties. Simply stated, the question arises on how much of the enhanced anti-tumoral activity of miRNA-drug combinations can be attributed to the alteration of tumor cell behavior, angiogenesis, or both. Finally, another important aspect is the toxicity potential from the miRNAs. We described above the side effects attributed to the clinically used anti-angiogenic therapies, which have a clinical history with well-defined side effects. In contrast, miRNAs have not achieved clinical translation to the same extent, and, thus, similar or other side effects may not yet have become apparent. Nonetheless, the utilization of dysregulated miRNAs, their property of being natural cell products, and the development of novel nanocarriers provide significant advantages to overcome side-effects, commonly present in traditional antiangiogenic therapies (160). In conclusion, miRNAs are fundamentally important targets and tools for cancer therapy. They have significant potential, based alone on their multifaceted activities on the tumor cells and tumor vascular microenvironment.

\section{REFERENCES}

1. Sajib S, Zahra FT, Lionakis MS, German NA, Mikelis CM. Mechanisms of Angiogenesis in Microbe-Regulated Inflammatory and Neoplastic Conditions. Angiogenesis (2018) 21:1-14. doi: 10.1007/s10456-017-9583-4

2. Zirlik K, Duyster J. Anti-Angiogenics: Current Situation and Future Perspectives. Oncol Res Treat (2018) 41:166-71. doi: 10.1159/000488087

3. Teleanu RI, Chircov C, Grumezescu AM, Teleanu DM. Tumor Angiogenesis and Anti-Angiogenic Strategies for Cancer Treatment. J Clin Med (2019) 9:84. doi: $10.3390 / \mathrm{jcm} 9010084$

4. Folkman J. Tumor Angiogenesis: Therapeutic Implications. N Engl J Med (1971) 285:1182-6. doi: 10.1056/NEJM197111182852108

5. Bielenberg DR, Zetter BR. The Contribution of Angiogenesis to the Process of Metastasis. Cancer J (2015) 21:267-73. doi: 10.1097/PPO.0000000000000138

6. Ramjiawan RR, Griffioen AW, Duda DG. Anti-Angiogenesis for Cancer Revisited: Is There a Role for Combinations With Immunotherapy? Angiogenesis (2017) 20:185-204. doi: 10.1007/s10456-017-9552-y

7. Zahra FT, Sajib MS, Ichiyama Y, Akwii RG, Tullar PE, Cobos C, et al. Endothelial RhoA GTPase Is Essential for In Vitro Endothelial Functions But Dispensable for Physiological In Vivo Angiogenesis. Sci Rep (2019) 9:11666. doi: 10.1038/s41598-019-48053-z

8. Zahra FT, Sajib MS, Mikelis CM. Role of bFGF in Acquired Resistance Upon AntiVEGF Therapy in Cancer. Cancers (2021) 13:1422. doi: 10.3390/cancers13061422

9. Schaaf MB, Garg AD, Agostinis P. Defining the Role of the Tumor Vasculature in Antitumor Immunity and Immunotherapy. Cell Death Dis (2018) 9:115. doi: 10.1038/s41419-017-0061-0

10. Carmeliet P, Jain RK. Principles and Mechanisms of Vessel Normalization for Cancer and Other Angiogenic Diseases. Nat Rev Drug Discov (2011) 10:417-27. doi: 10.1038/nrd3455

11. Jain RK. Antiangiogenesis Strategies Revisited: From Starving Tumors to Alleviating Hypoxia. Cancer Cell (2014) 26:605-22. doi: 10.1016/ j.ccell.2014.10.006

12. Huang Y, Goel S, Duda DG, Fukumura D, Jain RK. Vascular Normalization as an Emerging Strategy to Enhance Cancer Immunotherapy. Cancer Res (2013) 73:2943-8. doi: 10.1158/0008-5472.CAN-12-4354
Identification of miRNAs with combined anti-angiogenic and antitumoral effects can provide significant advantages in cancer treatment, alone or in combination with clinically used chemotherapeutics.

\section{AUTHOR CONTRIBUTIONS}

$\mathrm{BL}, \mathrm{SP}, \mathrm{CM}$, and GM contributed to the conception of the article, wrote and revised the final manuscript and agreed on its submission to this journal. All authors contributed to the article and approved the submitted version.

\section{FUNDING}

This work was supported for GM by the College of Pharmacy, University of Louisiana Monroe start-up funding and the National Institutes of Health (NIH) through the National Institute of General Medical Science Grants 5 P20 GM103424-15, 3 P20 GM103424-15S1 and for CM in part by National Institutes of Health Grant (NCI) R15CA231339 and Texas Tech University Health Sciences Center (TTUHSC) School of Pharmacy Office of Sciences grant. The funders had no role in study design, decision to write and preparation of the manuscript.

13. Peterson TE, Kirkpatrick ND, Huang Y, Farrar CT, Marijt KA, Kloepper J et al. Dual Inhibition of Ang-2 and VEGF Receptors Normalizes Tumor Vasculature and Prolongs Survival in Glioblastoma by Altering Macrophages. Proc Natl Acad Sci USA (2016) 113:4470-5. doi: 10.1073/ pnas. 1525349113

14. Mpekris F, Panagi M, Voutouri C, Martin JD, Samuel R, Takahashi S, et al. Normalizing the Microenvironment Overcomes Vessel Compression and Resistance to Nano-Immunotherapy in Breast Cancer Lung Metastasis. Adv Sci (Weinh) (2021) 8:2001917. doi: 10.1002/advs.202001917

15. Viallard C, Larrivee B. Tumor Angiogenesis and Vascular Normalization: Alternative Therapeutic Targets. Angiogenesis (2017) 20:409-26. doi: 10.1007/s10456-017-9562-9

16. Martinez-Rey D, Carmona-Rodriguez L, Fernandez-Acenero MJ, Mira E, Manes S. Extracellular Superoxide Dismutase, the Endothelial Basement Membrane, and the WNT Pathway: New Players in Vascular Normalization and Tumor Infiltration by T-Cells. Front Immunol (2020) 11:579552. doi 10.3389/fimmu.2020.579552

17. Si W, Shen J, Zheng H, Fan W. The Role and Mechanisms of Action of microRNAs in Cancer Drug Resistance. Clin Epigenet (2019) 11:25. doi: 10.1186/s13148-018-0587-8

18. Hossian AKMN, Mackenzie GG, Mattheolabakis G. Combination of Mir -143 and Mir-506 Reduces Lung and Pancreatic Cancer Cell Growth Through the Downregulation of Cyclin-Dependent Kinases. Oncol Rep (2021) 45:2. doi: 10.3892/or.2021.7953

19. Tahamtan A, Teymoori-Rad M, Nakstad B, Salimi V. Anti-Inflammatory MicroRNAs and Their Potential for Inflammatory Diseases Treatment. Front Immunol (2018) 9:1377. doi: 10.3389/fimmu.2018.01377

20. Chung JY, Thone MN, Kwon YJ. COVID-19 Vaccines: The Status and Perspectives in Delivery Points of View. Adv Drug Delivery Rev (2020) 170:1-25. doi: 10.1016/j.addr.2020.12.011

21. Chung YH, Beiss V, Fiering SN, Steinmetz NF. COVID-19 Vaccine Frontrunners and Their Nanotechnology Design. ACS Nano (2020) 14:12522-37. doi: 10.1021/acsnano.0c07197

22. Pushparajah D, Jimenez S, Wong S, Alattas H, Nafissi N, Slavcev RA. Advances in Gene-Based Vaccine Platforms to Address the COVID-19 
Pandemic. Adv Drug Delivery Rev (2021) 170:113-41. doi: 10.1016/ j.addr.2021.01.003

23. Labatut AE, Mattheolabakis G. Non-Viral Based miR Delivery and Recent Developments. Eur J Pharm Biopharm (2018) 128:82-90. doi: 10.1016/ j.ejpb.2018.04.018

24. Hossian A, Mackenzie GG, Mattheolabakis G. miRNAs in Gastrointestinal Diseases: Can We Effectively Deliver RNA-Based Therapeutics Orally? Nanomed (Lond) (2019) 14:2873-89. doi: 10.2217/nnm-2019-0180

25. Macha MA, Seshacharyulu P, Krishn SR, Pai P, Rachagani S, Jain M, et al. MicroRNAs (miRNAs) as Biomarker(s) for Prognosis and Diagnosis of Gastrointestinal (GI) Cancers. Curr Pharm Des (2014) 20:5287-97. doi: 10.2174/1381612820666140128213117

26. Mattheolabakis G, Mikelis CM. Nanoparticle Delivery and Tumor Vascular Normalization: The Chicken or The Egg? Front Oncol (2019) 9:1227. doi: 10.3389/fonc.2019.01227

27. Bader AG, Brown D, Winkler M. The Promise of microRNA Replacement Therapy. Cancer Res (2010) 70:7027-30. doi: 10.1158/0008-5472.CAN-10-2010

28. Li L, Yuan L, Luo J, Gao J, Guo J, Xie X. MiR-34a Inhibits Proliferation and Migration of Breast Cancer Through Down-Regulation of Bcl-2 and SIRT1. Clin Exp Med (2013) 13:109-17. doi: 10.1007/s10238-012-0186-5

29. Wang JX, Zhang QJ, Pei SG, Yang BL. Effect and Mechanism of miR-34a on Proliferation, Apoptosis and Invasion of Laryngeal Carcinoma Cells. Asian Pac J Trop Med (2016) 9:494-8. doi: 10.1016/j.apjtm.2016.03.018

30. Zhang L, Liao Y, Tang L. MicroRNA-34 Family: A Potential Tumor Suppressor and Therapeutic Candidate in Cancer. J Exp Clin Cancer Res (2019) 38:53. doi: 10.1186/s13046-019-1059-5

31. Bonneau E, Neveu B, Kostantin E, Tsongalis GJ, De Guire V. How Close Are miRNAs From Clinical Practice? A Perspective on the Diagnostic and Therapeutic Market. EJIFCC (2019) 30:114-27. doi: 10.3389/ fgene. 2019.00478

32. Hanna J, Hossain GS, Kocerha J. The Potential for microRNA Therapeutics and Clinical Research. Front Genet (2019) 10:478. doi: 10.3389/ fgene.2019.00478

33. Chakraborty C, Sharma AR, Sharma G, Lee SS. Therapeutic Advances of miRNAs: A Preclinical and Clinical Update. J Adv Res (2021) 28:127-38. doi: 10.1016/j.jare.2020.08.012

34. Landskroner-Eiger S, Moneke I, Sessa WC. miRNAs as Modulators of Angiogenesis. Cold Spring Harb Perspect Med (2013) 3:a006643. doi: 10.1101/cshperspect.a006643

35. Peng Y, Croce CM. The Role of MicroRNAs in Human Cancer. Signal Transduct Target Ther (2016) 1:15004. doi: 10.1038/sigtrans.2015.4

36. Fish JE, Srivastava D. MicroRNAs: Opening a New Vein in Angiogenesis Research. Sci Signal (2009) 2:pe1. doi: 10.1126/scisignal.252pe1

37. Finn NA, Searles CD. Intracellular and Extracellular miRNAs in Regulation of Angiogenesis Signaling. Curr Angiogenes (2012) 4:299-307. doi: 10.2174/ 2211552811201040299

38. Ma J, Waxman DJ. Combination of Antiangiogenesis With Chemotherapy for More Effective Cancer Treatment. Mol Cancer Ther (2008) 7:3670-84. doi: 10.1158/1535-7163.MCT-08-0715

39. Senger DR, Galli SJ, Dvorak AM, Perruzzi CA, Harvey VS, Dvorak HF. Tumor Cells Secrete a Vascular Permeability Factor That Promotes Accumulation of Ascites Fluid. Science (1983) 219:983-5. doi: 10.1126/ science. 6823562

40. Leung DW, Cachianes G, Kuang WJ, Goeddel DV, Ferrara N. Vascular Endothelial Growth Factor Is a Secreted Angiogenic Mitogen. Science (1989) 246:1306-9. doi: 10.1126/science.2479986

41. Carmeliet P, Ferreira V, Breier G, Pollefeyt S, Kieckens L, Gertsenstein M, et al. Abnormal Blood Vessel Development and Lethality in Embryos Lacking a Single VEGF Allele. Nature (1996) 380:435-9. doi: 10.1038/ $380435 \mathrm{a} 0$

42. Ferrara N, Carver-Moore K, Chen H, Dowd M, Lu L, O'shea KS, et al. Heterozygous Embryonic Lethality Induced by Targeted Inactivation of the VEGF Gene. Nature (1996) 380:439-42. doi: 10.1038/380439a0

43. Ferrara N, Hillan KJ, Novotny W. Bevacizumab (Avastin), a Humanized Anti-VEGF Monoclonal Antibody for Cancer Therapy. Biochem Biophys Res Commun (2005) 333:328-35. doi: 10.1016/j.bbrc.2005.05.132

44. Ferrara N, Kerbel RS. Angiogenesis as a Therapeutic Target. Nature (2005) 438:967-74. doi: 10.1038/nature04483
45. Hurwitz H, Fehrenbacher L, Novotny W, Cartwright T, Hainsworth J, Heim $\mathrm{W}$, et al. Bevacizumab Plus Irinotecan, Fluorouracil, and Leucovorin for Metastatic Colorectal Cancer. N Engl J Med (2004) 350:2335-42. doi: 10.1056/NEJMoa032691

46. Herbst RS, Heymach JV, O'reilly MS, Onn A, Ryan AJ. Vandetanib (ZD6474): An Orally Available Receptor Tyrosine Kinase Inhibitor That Selectively Targets Pathways Critical for Tumor Growth and Angiogenesis. Expert Opin Investig Drugs (2007) 16:239-49. doi: 10.1517/13543784. 16.2.239

47. Houghton PJ. Everolimus. Clin Cancer Res (2010) 16:1368-72. doi: 10.1158/ 1078-0432.CCR-09-1314

48. Govindaraj C, Madondo M, Kong YY, Tan P, Wei A, Plebanski M. Lenalidomide-Based Maintenance Therapy Reduces TNF Receptor 2 on CD4 T Cells and Enhances Immune Effector Function in Acute Myeloid Leukemia Patients. Am J Hematol (2014) 89:795-802. doi: 10.1002/ ajh. 23746

49. Fink EC, Ebert BL. The Novel Mechanism of Lenalidomide Activity. Blood (2015) 126:2366-9. doi: 10.1182/blood-2015-07-567958

50. Hsieh JJ, Purdue MP, Signoretti S, Swanton C, Albiges L, Schmidinger M, et al. Renal Cell Carcinoma. Nat Rev Dis Primers (2017) 3:17009. doi: 10.1038/nrdp.2017.9

51. Zhu YJ, Zheng B, Wang HY, Chen L. New Knowledge of the Mechanisms of Sorafenib Resistance in Liver Cancer. Acta Pharmacol Sin (2017) 38:614-22. doi: 10.1038/aps.2017.5

52. Abou-Alfa GK, Meyer T, Cheng AL, El-Khoueiry AB, Rimassa L, Ryoo BY, et al. Cabozantinib in Patients With Advanced and Progressing Hepatocellular Carcinoma. N Engl J Med (2018) 379:54-63. doi: 10.1056/ NEJMoa1717002

53. Nci. Angiogenesis Inhibitors (2018). Available at: https://www.cancer.gov/ about-cancer/treatment/types/immunotherapy/angiogenesis-inhibitorsfact-sheet (Accessed 3.24 2021)

54. Fondevila F, Mendez-Blanco C, Fernandez-Palanca P, Gonzalez-Gallego J, Mauriz JL. Anti-Tumoral Activity of Single and Combined Regorafenib Treatments in Preclinical Models of Liver and Gastrointestinal Cancers. Exp Mol Med (2019) 51:1-15. doi: 10.1038/s12276-019-0308-1

55. Ebos JM, Lee CR, Cruz-Munoz W, Bjarnason GA, Christensen JG, Kerbel RS. Accelerated Metastasis After Short-Term Treatment With a Potent Inhibitor of Tumor Angiogenesis. Cancer Cell (2009) 15:232-9. doi: 10.1016/j.ccr.2009.01.021

56. Paez-Ribes M, Allen E, Hudock J, Takeda T, Okuyama H, Vinals F, et al. Antiangiogenic Therapy Elicits Malignant Progression of Tumors to Increased Local Invasion and Distant Metastasis. Cancer Cell (2009) 15:220-31. doi: 10.1016/j.ccr.2009.01.027

57. Wang D, Tan C, Xiao F, Zou L, Wang L, Wei Y, et al. The "Inherent Vice" in the Anti-Angiogenic Theory may Cause the Highly Metastatic Cancer to Spread More Aggressively. Sci Rep (2017) 7:2365. doi: 10.1038/s41598-01702534-1

58. Lugano R, Ramachandran M, Dimberg A. Tumor Angiogenesis: Causes, Consequences, Challenges and Opportunities. Cell Mol Life Sci (2020) 77:1745-70. doi: 10.1007/s00018-019-03351-7

59. Rust R, Gantner C, Schwab ME. Pro- and Antiangiogenic Therapies: Current Status and Clinical Implications. FASEB J (2019) 33:34-48. doi: 10.1096/ fj.201800640RR

60. Scappaticci FA, Skillings JR, Holden SN, Gerber HP, Miller K, Kabbinavar F, et al. Arterial Thromboembolic Events in Patients With Metastatic Carcinoma Treated With Chemotherapy and Bevacizumab. J Natl Cancer Inst (2007) 99:1232-9. doi: 10.1093/jnci/djm086

61. Chen HX, Cleck JN. Adverse Effects of Anticancer Agents That Target the VEGF Pathway. Nat Rev Clin Oncol (2009) 6:465-77. doi: 10.1038/nrclinonc.2009.94

62. Touyz RM, Lang NN, Herrmann J, Van Den Meiracker AH, Danser AHJ. Recent Advances in Hypertension and Cardiovascular Toxicities With Vascular Endothelial Growth Factor Inhibition. Hypertension (2017) 70:220-6. doi: 10.1161/HYPERTENSIONAHA.117.08856

63. Touyz RM, Herrmann J. Cardiotoxicity With Vascular Endothelial Growth Factor Inhibitor Therapy. NPJ Precis Oncol (2018) 2:13. doi: 10.1038/s41698018-0056-z

64. Seymour JF, Pfreundschuh M, Trneny M, Sehn LH, Catalano J, Csinady E, et al. R-CHOP With or Without Bevacizumab in Patients With Previously 
Untreated Diffuse Large B-Cell Lymphoma: Final MAIN Study Outcomes. Haematologica (2014) 99:1343-9. doi: 10.3324/haematol.2013.100818

65. Bailey CE, Parikh AA. Assessment of the Risk of Antiangiogenic Agents Before and After Surgery. Cancer Treat Rev (2018) 68:38-46. doi: 10.1016/ j.ctrv.2018.05.002

66. Bodnar RJ. Anti-Angiogenic Drugs: Involvement in Cutaneous Side Effects and Wound-Healing Complication. Adv Wound Care (New Rochelle) (2014) 3:635-46. doi: 10.1089/wound.2013.0496

67. Davis-Dusenbery BN, Hata A. MicroRNA in Cancer: The Involvement of Aberrant MicroRNA Biogenesis Regulatory Pathways. Genes Cancer (2010) 1:1100-14. doi: 10.1177/1947601910396213

68. Wang Y, Wang L, Chen C, Chu X. New Insights Into the Regulatory Role of microRNA in Tumor Angiogenesis and Clinical Implications. Mol Cancer (2018) 17:22. doi: 10.1186/s12943-018-0766-4

69. Hu J, Cheng Y, Li Y, Jin Z, Pan Y, Liu G, et al. microRNA-128 Plays a Critical Role in Human Non-Small Cell Lung Cancer Tumourigenesis, Angiogenesis and Lymphangiogenesis by Directly Targeting Vascular Endothelial Growth Factor-C. Eur J Cancer (2014) 50:2336-50. doi: 10.1016/j.ejca.2014.06.005

70. Yang L, Dong C, Yang J, Yang L, Chang N, Qi C, et al. MicroRNA-26b-5p Inhibits Mouse Liver Fibrogenesis and Angiogenesis by Targeting PDGF Receptor-Beta. Mol Ther Nucleic Acids (2019) 16:206-17. doi: 10.1016/ j.omtn.2019.02.014

71. Sun T, Yin L, Kuang H. miR-181a/B-5p Regulates Human Umbilical Vein Endothelial Cell Angiogenesis by Targeting PDGFRA. Cell Biochem Funct (2020) 38:222-30. doi: 10.1002/cbf.3472

72. Yamakuchi M, Ferlito M, Lowenstein CJ. miR-34a Repression of SIRT1 Regulates Apoptosis. Proc Natl Acad Sci USA (2008) 105:13421-6. doi: 10.1073/pnas.0801613105

73. Zhao T, Li J, Chen AF. MicroRNA-34a Induces Endothelial Progenitor Cell Senescence and Impedes Its Angiogenesis via Suppressing Silent Information Regulator 1. Am J Physiol Endocrinol Metab (2010) 299: E110-116. doi: 10.1152/ajpendo.00192.2010

74. Tabuchi T, Satoh M, Itoh T, Nakamura M. MicroRNA-34a Regulates the Longevity-Associated Protein SIRT1 in Coronary Artery Disease: Effect of Statins on SIRT1 and microRNA-34a Expression. Clin Sci (Lond) (2012) 123:161-71. doi: 10.1042/CS20110563

75. Shi S, Jin Y, Song H, Chen X. MicroRNA-34a Attenuates VEGF-Mediated Retinal Angiogenesis via Targeting Notch1. Biochem Cell Biol (2019) 97:423-30. doi: 10.1139/bcb-2018-0304

76. Yu G, Yao W, Xiao W, Li H, Xu H, Lang B. MicroRNA-34a Functions as an Anti-Metastatic microRNA and Suppresses Angiogenesis in Bladder Cancer by Directly Targeting CD44. J Exp Clin Cancer Res (2014) 33:779. doi: 10.1186/s13046-014-0115-4

77. Su G, Sun G, Liu H, Shu L, Liang Z. Downregulation of miR-34a Promotes Endothelial Cell Growth and Suppresses Apoptosis in Atherosclerosis by Regulating Bcl-2. Heart Vessels (2018) 33:1185-94. doi: 10.1007/s00380-018$1169-6$

78. Vinall RL, Ripoll AZ, Wang S, Pan CX, Devere White RW. MiR-34a Chemosensitizes Bladder Cancer Cells to Cisplatin Treatment Regardless of P53-Rb Pathway Status. Int J Cancer (2012) 130:2526-38. doi: 10.1002/ijc.26256

79. Song C, Lu P, Sun G, Yang L, Wang Z, Wang Z. miR-34a Sensitizes Lung Cancer Cells to Cisplatin via P53/miR-34a/MYCN Axis. Biochem Biophys Res Commun (2017) 482:22-7. doi: 10.1016/j.bbrc.2016.11.037

80. Zheng SZ, Sun P, Wang JP, Liu Y, Gong W, Liu J. MiR-34a Overexpression Enhances the Inhibitory Effect of Doxorubicin on HepG2 Cells. World J Gastroenterol (2019) 25:2752-62. doi: 10.3748/wjg.v25.i22.2752

81. Jian C, Tu MJ, Ho PY, Duan Z, Zhang Q, Qiu JX, et al. Co-Targeting of DNA, RNA, and Protein Molecules Provides Optimal Outcomes for Treating Osteosarcoma and Pulmonary Metastasis in Spontaneous and Experimental Metastasis Mouse Models. Oncotarget (2017) 8:30742-55. doi: 10.18632 /oncotarget.16372

82. Wen D, Peng Y, Lin F, Singh RK, Mahato RI. Micellar Delivery of miR-34a Modulator Rubone and Paclitaxel in Resistant Prostate Cancer. Cancer Res (2017) 77:3244-54. doi: 10.1158/0008-5472.CAN-16-2355

83. Fang JH, Zhou HC, Zeng C, Yang J, Liu Y, Huang X, et al. MicroRNA-29b Suppresses Tumor Angiogenesis, Invasion, and Metastasis by Regulating Matrix Metalloproteinase 2 Expression. Hepatology (2011) 54:1729-40. doi: 10.1002/hep.24577
84. Kriegel AJ, Liu Y, Fang Y, Ding X, Liang M. The miR-29 Family: Genomics, Cell Biology, and Relevance to Renal and Cardiovascular Injury. Physiol Genomics (2012) 44:237-44. doi: 10.1152/physiolgenomics.00141.2011

85. Chen HX, Xu XX, Tan BZ, Zhang Z, Zhou XD. MicroRNA-29b Inhibits Angiogenesis by Targeting VEGFA Through the MAPK/ERK and PI3K/Akt Signaling Pathways in Endometrial Carcinoma. Cell Physiol Biochem (2017) 41:933-46. doi: 10.1159/000460510

86. Li Y, Cai B, Shen L, Dong Y, Lu Q, Sun S, et al. MiRNA-29b Suppresses Tumor Growth Through Simultaneously Inhibiting Angiogenesis and Tumorigenesis by Targeting Akt3. Cancer Lett (2017) 397:111-9. doi: 10.1016/j.canlet.2017.03.032

87. Zhang H, Bai M, Deng T, Liu R, Wang X, Qu Y, et al. Cell-Derived Microvesicles Mediate the Delivery of miR-29a/C to Suppress Angiogenesis in Gastric Carcinoma. Cancer Lett (2016) 375:331-9. doi: 10.1016/j.canlet.2016.03.026

88. Sun DM, Tang BF, Li ZX, Guo HB, Cheng JL, Song PP, et al. MiR-29c Reduces the Cisplatin Resistance of Non-Small Cell Lung Cancer Cells by Negatively Regulating the PI3K/Akt Pathway. Sci Rep (2018) 8:8007. doi: 10.1038/s41598-018-26381-w

89. Huang L, Hu C, Chao H, Wang R, Lu H, Li H, et al. miR-29c Regulates Resistance to Paclitaxel in Nasopharyngeal Cancer by Targeting ITGB1. Exp Cell Res (2019) 378:1-10. doi: 10.1016/j.yexcr.2019.02.012

90. Shen H, Li L, Yang S, Wang D, Zhong S, Zhao J, et al. MicroRNA-29a Contributes to Drug-Resistance of Breast Cancer Cells to Adriamycin Through PTEN/AKT/GSK3beta Signaling Pathway. Gene (2016) 593:8490. doi: 10.1016/j.gene.2016.08.016

91. Shi X, Valizadeh A, Mir SM, Asemi Z, Karimian A, Majidina M, et al. miRNA-29a Reverses P-Glycoprotein-Mediated Drug Resistance and Inhibits Proliferation via Up-Regulation of PTEN in Colon Cancer Cells. Eur J Pharmacol (2020) 880:173138. doi: 10.1016/j.ejphar.2020. 173138

92. Li Y, Zhang Z, Xiao Z, Lin Y, Luo T, Zhou Q, et al. Chemotherapy-Mediated miR-29b Expression Inhibits the Invasion and Angiogenesis of Cervical Cancer. Oncotarget (2017) 8:14655-65. doi: 10.18632/oncotarget.14738

93. Poliseno L, Tuccoli A, Mariani L, Evangelista M, Citti L, Woods K, et al. MicroRNAs Modulate the Angiogenic Properties of HUVECs. Blood (2006) 108:3068-71. doi: 10.1182/blood-2006-01-012369

94. Bartel DP. MicroRNAs: Target Recognition and Regulatory Functions. Cell (2009) 136:215-33. doi: 10.1016/j.cell.2009.01.002

95. Nicoli S, Knyphausen CP, Zhu LJ, Lakshmanan A, Lawson ND. miR-221 Is Required for Endothelial Tip Cell Behaviors During Vascular Development. Dev Cell (2012) 22:418-29. doi: 10.1016/j.devcel.2012.01.008

96. Chen Y, Banda M, Speyer CL, Smith JS, Rabson AB, Gorski DH. Regulation of the Expression and Activity of the Antiangiogenic Homeobox Gene GAX/ MEOX2 by ZEB2 and microRNA-221. Mol Cell Biol (2010) 30:3902-13. doi: 10.1128/MCB.01237-09

97. Wu YH, Hu TF, Chen YC, Tsai YN, Tsai YH, Cheng CC, et al. The Manipulation of miRNA-Gene Regulatory Networks by KSHV Induces Endothelial Cell Motility. Blood (2011) 118:2896-905. doi: 10.1182/blood2011-01-330589

98. Li Y, Yan C, Fan J, Hou Z, Han Y. MiR-221-3p Targets Hif-1alpha to Inhibit Angiogenesis in Heart Failure. Lab Invest (2021) 101:104-15. doi: 10.1038/ s41374-020-0450-3

99. Mercatelli N, Coppola V, Bonci D, Miele F, Costantini A, Guadagnoli M, et al. The Inhibition of the Highly Expressed miR-221 and miR-222 Impairs the Growth of Prostate Carcinoma Xenografts in Mice. PloS One (2008) 3: e4029. doi: 10.1371/journal.pone.0004029

100. Le Sage C, Nagel R, Egan DA, Schrier M, Mesman E, Mangiola A, et al. Regulation of the P27(Kip1) Tumor Suppressor by miR-221 and miR-222 Promotes Cancer Cell Proliferation. EMBO J (2007) 26:3699-708. doi: 10.1038/s.emboj.7601790

101. Miller TE, Ghoshal K, Ramaswamy B, Roy S, Datta J, Shapiro CL, et al. MicroRNA-221/222 Confers Tamoxifen Resistance in Breast Cancer by Targeting p27Kip1. J Biol Chem (2008) 283:29897-903. doi: 10.1074/ jbc.M804612200

102. Garofalo M, Quintavalle C, Di Leva G, Zanca C, Romano G, Taccioli C, et al. MicroRNA Signatures of TRAIL Resistance in Human Non-Small Cell Lung Cancer. Oncogene (2008) 27:3845-55. doi: 10.1038/onc.2008.6 
103. Amini-Farsani Z, Sangtarash MH, Shamsara M, Teimori H. MiR-221/222 Promote Chemoresistance to Cisplatin in Ovarian Cancer Cells by Targeting PTEN/PI3K/AKT Signaling Pathway. Cytotechnology (2018) 70:203-13. doi: 10.1007/s10616-017-0134-Z

104. Li S, Li Q, Lu J, Zhao Q, Li D, Shen L, et al. Targeted Inhibition of miR-221/ 222 Promotes Cell Sensitivity to Cisplatin in Triple-Negative Breast Cancer MDA-MB-231 Cells. Front Genet (2019) 10:1278. doi: 10.3389/ fgene. 2019.01278

105. Chen D, Yan W, Liu Z, Zhang Z, Zhu L, Liu W, et al. Downregulation of miR-221 Enhances the Sensitivity of Human Oral Squamous Cell Carcinoma Cells to Adriamycin Through Upregulation of TIMP3 Expression. BioMed Pharmacother (2016) 77:72-8. doi: 10.1016/j.biopha.2015.12.002

106. Du L, Ma S, Wen X, Chai J, Zhou D. Oral Squamous Cell Carcinoma Cells Are Resistant to Doxorubicin Through Upregulation of Mir221. Mol Med Rep (2017) 16:2659-67. doi: 10.3892/mmr.2017.6915

107. Wang Y, Zhao Y, Herbst A, Kalinski T, Qin J, Wang X, et al. miR-221 Mediates Chemoresistance of Esophageal Adenocarcinoma by Direct Targeting of DKK2 Expression. Ann Surg (2016) 264:804-14. doi: 10.1097/ SLA.0000000000001928

108. Ni L, Xu J, Zhao F, Dai X, Tao J, Pan J, et al. MiR-221-3p-Mediated Downregulation of MDM2 Reverses the Paclitaxel Resistance of Non-Small Cell Lung Cancer In Vitro and In Vivo. Eur J Pharmacol (2021) 899:174054. doi: 10.1016/j.ejphar.2021.174054

109. Lei Z, Li B, Yang Z, Fang H, Zhang GM, Feng ZH, et al. Regulation of HIF1alpha and VEGF by miR-20b Tunes Tumor Cells to Adapt to the Alteration of Oxygen Concentration. PloS One (2009) 4:e7629. doi: 10.1371/ journal.pone.0007629

110. Chou J, Lin JH, Brenot A, Kim JW, Provot S, Werb Z. GATA3 Suppresses Metastasis and Modulates the Tumour Microenvironment by Regulating microRNA-29b Expression. Nat Cell Biol (2013) 15:201-13. doi: 10.1038/ ncb2672

111. Long J, Wang Y, Wang W, Chang BH, Danesh FR. Identification of microRNA-93 as a Novel Regulator of Vascular Endothelial Growth Factor in Hyperglycemic Conditions. J Biol Chem (2010) 285:23457-65. doi: 10.1074/jbc.M110.136168

112. Li F, Liang X, Chen Y, Li S, Liu J. Role of microRNA-93 in Regulation of Angiogenesis. Tumour Biol (2014) 35:10609-13. doi: 10.1007/s13277-0142605-6

113. Tirpe A, Gulei D, Tirpe GR, Nutu A, Irimie A, Campomenosi P, et al. Beyond Conventional: The New Horizon of Anti-Angiogenic microRNAs in NonSmall Cell Lung Cancer Therapy. Int J Mol Sci (2020) 21:8002. doi: 10.3390/ ijms 21218002

114. Chen Q, Chen S, Zhao J, Zhou Y, Xu L. MicroRNA-126: A New and Promising Player in Lung Cancer. Oncol Lett (2021) 21:35. doi: 10.3892/ ol.2020.12296

115. Ye J, Wu X, Wu D, Wu P, Ni C, Zhang Z, et al. miRNA-27b Targets Vascular Endothelial Growth Factor C to Inhibit Tumor Progression and Angiogenesis in Colorectal Cancer. PloS One (2013) 8:e60687. doi: 10.1371/journal.pone.0060687

116. Liu HT, Xing AY, Chen X, Ma RR, Wang YW, Shi DB, et al. MicroRNA-27b, microRNA-101 and microRNA-128 Inhibit Angiogenesis by DownRegulating Vascular Endothelial Growth Factor C Expression in Gastric Cancers. Oncotarget (2015) 6:37458-70. doi: 10.18632/oncotarget.6059

117. Muramatsu F, Kidoya H, Naito H, Sakimoto S, Takakura N. microRNA-125b Inhibits Tube Formation of Blood Vessels Through Translational Suppression of VE-Cadherin. Oncogene (2013) 32:414-21. doi: 10.1038/onc.2012.68

118. Wu SY, Rupaimoole R, Shen F, Pradeep S, Pecot CV, Ivan C, et al. A miR192-EGR1-HOXB9 Regulatory Network Controls the Angiogenic Switch in Cancer. Nat Commun (2016) 7:11169. doi: 10.1038/ncomms11169

119. Pecot CV, Rupaimoole R, Yang D, Akbani R, Ivan C, Lu C, et al. Tumour Angiogenesis Regulation by the miR-200 Family. Nat Commun (2013) 4:2427. doi: $10.1038 /$ ncomms 3427

120. Sun G, Liu M, Han H. Overexpression of microRNA-190 Inhibits Migration, Invasion, Epithelial-Mesenchymal Transition, and Angiogenesis Through Suppression of Protein Kinase B-Extracellular Signal-Regulated Kinase Signaling Pathway via Binding to Stanniocalicin 2 in Breast Cancer. J Cell Physiol (2019) 234:17824-38. doi: 10.1002/jcp.28409
121. Chen QY, Jiao DM, Wu YQ, Chen J, Wang J, Tang XL, et al. MiR-206 Inhibits HGF-Induced Epithelial-Mesenchymal Transition and Angiogenesis in Non-Small Cell Lung Cancer via C-Met /PI3k/Akt/mTOR Pathway. Oncotarget (2016) 7:18247-61. doi: 10.18632/oncotarget.7570

122. Zhou Y, Li S, Li J, Wang D, Li Q. Effect of microRNA-135a on Cell Proliferation, Migration, Invasion, Apoptosis and Tumor Angiogenesis Through the IGF-1/PI3K/Akt Signaling Pathway in Non-Small Cell Lung Cancer. Cell Physiol Biochem (2017) 42:1431-46. doi: 10.1159/000479207

123. Hossian A, Sajib MS, Tullar PE, Mikelis CM, Mattheolabakis G. Multipronged Activity of Combinatorial miR-143 and miR-506 Inhibits Lung Cancer Cell Cycle Progression and Angiogenesis. Vitro Sci Rep (2018) 8:10495. doi: 10.1038/s41598-018-28872-2

124. Belcheva A, Wey JS, Fan F, Ellis LM. Expression of Vascular Endothelial Growth Factor Receptors (VEGF-Rs) on Human Breast Cancer Cells Confers Chemoresistance. Cancer Res (2004) 64:1000.

125. Stanton MJ, Dutta S, Zhang H, Polavaram NS, Leontovich AA, Honscheid P, et al. Autophagy Control by the VEGF-C/NRP-2 Axis in Cancer and Its Implication for Treatment Resistance. Cancer Res (2013) 73:160-71. doi: 10.1158/0008-5472.CAN-11-3635

126. Wang CA, Harrell JC, Iwanaga R, Jedlicka P, Ford HL. Vascular Endothelial Growth Factor C Promotes Breast Cancer Progression via a Novel Antioxidant Mechanism That Involves Regulation of Superoxide Dismutase 3. Breast Cancer Res (2014) 16:462. doi: 10.1186/s13058-0140462-2

127. Zhu X, Li H, Long L, Hui L, Chen H, Wang X, et al. miR-126 Enhances the Sensitivity of Non-Small Cell Lung Cancer Cells to Anticancer Agents by Targeting Vascular Endothelial Growth Factor A. Acta Biochim Biophys Sin (Shanghai) (2012) 44:519-26. doi: 10.1093/abbs/gms026

128. Zhao Y, Tu MJ, Yu YF, Wang WP, Chen QX, Qiu JX, et al. Combination Therapy With Bioengineered miR-34a Prodrug and Doxorubicin Synergistically Suppresses Osteosarcoma Growth. Biochem Pharmacol (2015) 98:602-13. doi: 10.1016/j.bcp.2015.10.015

129. Yu J, Zhao Y, Liu C, Hu B, Zhao M, Ma Y, et al. Synergistic Anti-Tumor Effect of Paclitaxel and miR-34a Combined With Ultrasound Microbubbles on Cervical Cancer In Vivo and In Vitro. Clin Transl Oncol (2020) 22:60-9. doi: 10.1007/s12094-019-02131-w

130. Shi S, Han L, Deng L, Zhang Y, Shen H, Gong T, et al. Dual Drugs (microRNA-34a and Paclitaxel)-Loaded Functional Solid Lipid Nanoparticles for Synergistic Cancer Cell Suppression. J Control Release (2014) 194:228-37. doi: 10.1016/j.jconrel.2014.09.005

131. Soltani-Sedeh H, Irani S, Mirfakhraie R, Soleimani M. Potential Using of microRNA-34A in Combination With Paclitaxel in Colorectal Cancer Cells. J Cancer Res Ther (2019) 15:32-7. doi: 10.4103/jcrt.JCRT_267_17

132. Zhang L, Yang X, Lv Y, Xin X, Qin C, Han X, et al. Cytosolic Co-Delivery of miRNA-34a and Docetaxel With Core-Shell Nanocarriers via CaveolaeMediated Pathway for the Treatment of Metastatic Breast Cancer. Sci Rep (2017) 7:46186. doi: 10.1038/srep46186

133. Zhang Q, Wang J, Li N, Liu Z, Chen Z, Li Z, et al. miR-34a Increases the Sensitivity of Colorectal Cancer Cells to 5-Fluorouracil In Vitro and In Vivo. Am J Cancer Res (2018) 8:280-90.

134. Xu J, Zhang G, Luo X, Wang D, Zhou W, Zhang Y, et al. Co-Delivery of 5Fluorouracil and miRNA-34a Mimics by Host-Guest Self-Assembly Nanocarriers for Efficacious Targeted Therapy in Colorectal Cancer Patient-Derived Tumor Xenografts. Theranostics (2021) 11:2475-89. doi: 10.7150/thno.52076

135. Jilek JL, Tu MJ, Zhang C, Yu AM. Pharmacokinetic and Pharmacodynamic Factors Contribute to Synergism Between Let-7c-5p and 5-Fluorouracil in Inhibiting Hepatocellular Carcinoma Cell Viability. Drug Metab Dispos (2020) 48:1257-63. doi: 10.1124/dmd.120.000207

136. Costa PM, Cardoso AL, Custodia C, Cunha P, Pereira De Almeida L, Pedroso De Lima MC. MiRNA-21 Silencing Mediated by Tumor-Targeted Nanoparticles Combined With Sunitinib: A New Multimodal Gene Therapy Approach for Glioblastoma. J Control Release (2015) 207:31-9. doi: 10.1016/j.jconrel.2015.04.002

137. Passadouro M, Pedroso De Lima MC, Faneca H. MicroRNA Modulation Combined With Sunitinib as a Novel Therapeutic Strategy for Pancreatic Cancer. Int J Nanomed (2014) 9:3203-17. doi: 10.2147/IJN.S64456 
138. Liu H, Liu Z, Jiang B, Huo L, Liu J, Lu J. Synthetic miR-145 Mimic Enhances the Cytotoxic Effect of the Antiangiogenic Drug Sunitinib in Glioblastoma. Cell Biochem Biophys (2015) 72:551-7. doi: 10.1007/s12013-014-0501-8

139. Kim SJ, Oh JS, Shin JY, Lee KD, Sung KW, Nam SJ, et al. Development of microRNA-145 for Therapeutic Application in Breast Cancer. J Control Release (2011) 155:427-34. doi: 10.1016/j.jconrel.2011.06.026

140. Mittal A, Chitkara D, Behrman SW, Mahato RI. Efficacy of Gemcitabine Conjugated and miRNA-205 Complexed Micelles for Treatment of Advanced Pancreatic Cancer. Biomaterials (2014) 35:7077-87. doi: 10.1016/j.biomaterials.2014.04.053

141. Karaayvaz M, Zhai H, Ju J. miR-129 Promotes Apoptosis and Enhances Chemosensitivity to 5-Fluorouracil in Colorectal Cancer. Cell Death Dis (2013) 4:e659. doi: 10.1038/cddis.2013.193

142. Liu L, Zheng W, Song Y, Du X, Tang Y, Nie J, et al. miRNA-497 Enhances the Sensitivity of Colorectal Cancer Cells to Neoadjuvant Chemotherapeutic Drug. Curr Protein Pept Sci (2015) 16:310-5. doi: 10.2174/1389203716041 50429154142

143. Zhang G, Tian X, Li Y, Wang Z, Li X, Zhu C. miR-27b and miR-34a Enhance Docetaxel Sensitivity of Prostate Cancer Cells Through Inhibiting Epithelialto-Mesenchymal Transition by Targeting ZEB1. BioMed Pharmacother (2018) 97:736-44. doi: 10.1016/j.biopha.2017.10.163

144. Hu H, Wang Z, Tan C, Liu X, Zhang H, Li K. Dihydroartemisinin/miR-29b Combination Therapy Increases the Pro-Apoptotic Effect of Dihydroartemisinin on Cholangiocarcinoma Cell Lines by Regulating Mcl-1 Expression. Adv Clin Exp Med (2020) 29:911-9. doi: 10.17219/acem/121919

145. Lee J, Choi KJ, Moon SU, Kim S. Theragnosis-Based Combined Cancer Therapy Using Doxorubicin-Conjugated microRNA-221 Molecular Beacon. Biomaterials (2016) 74:109-18. doi: 10.1016/j.biomaterials.2015.09.036

146. Zhang Y, He Y, Lu LL, Zhou ZY, Wan NB, Li GP, et al. miRNA-192-5p Impacts the Sensitivity of Breast Cancer Cells to Doxorubicin via Targeting Peptidylprolyl Isomerase A. Kaohsiung J Med Sci (2019) 35:17-23. doi: $10.1002 / \mathrm{kjm} 2.12004$

147. Fu H, Zhang J, Pan T, Ai S, Tang L, Wang F. Mir378a Enhances the Sensitivity of Liver Cancer to Sorafenib by Targeting VEGFR, PDGFRbeta and Craf. Mol Med Rep (2018) 17:4581-8. doi: 10.3892/mmr.2018.8390

148. Xu H, Zhao L, Fang Q, Sun J, Zhang S, Zhan C, et al. MiR-338-3p Inhibits Hepatocarcinoma Cells and Sensitizes These Cells to Sorafenib by Targeting Hypoxia-Induced Factor 1alpha. PloS One (2014) 9:e115565. doi: 10.1371/ journal.pone.0115565

149. Hejazi M, Baghbani E, Amini M, Rezaei T, Aghanejad A, Mosafer J, et al. MicroRNA-193a and Taxol Combination: A New Strategy for Treatment of Colorectal Cancer. J Cell Biochem (2020) 121:1388-99. doi: 10.1002/jcb.29374

150. Esfandyari YB, Doustvandi MA, Amini M, Baradaran B, Zaer SJ, Mozammel N, et al. MicroRNA-143 Sensitizes Cervical Cancer Cells to Cisplatin: A Promising Anticancer Combination Therapy. Reprod Sci (2021) 28:2036-49. doi: 10.1007/s43032-021-00479-5

151. Yu PN, Yan MD, Lai HC, Huang RL, Chou YC, Lin WC, et al. Downregulation of miR-29 Contributes to Cisplatin Resistance of Ovarian Cancer Cells. Int J Cancer (2014) 134:542-51. doi: 10.1002/ijc.28399

152. Gajda E, Godlewska M, Mariak Z, Nazaruk E, Gawel D. Combinatory Treatment With miR-7-5p and Drug-Loaded Cubosomes Effectively
Impairs Cancer Cells. Int J Mol Sci (2020) 21:5039. doi: 10.3390/ ijms 21145039

153. Sun Y, Wu J, Dong X, Zhang J, Meng C, Liu G. MicroRNA-506-3p Increases the Response to PARP Inhibitors and Cisplatin by Targeting EZH2/betaCatenin in Serous Ovarian Cancers. Transl Oncol (2021) 14:100987. doi: 10.1016/j.tranon.2020.100987

154. Golubovskaya VM, Sumbler B, Ho B, Yemma M, Cance WG. MiR-138 and MiR-135 Directly Target Focal Adhesion Kinase, Inhibit Cell Invasion, and Increase Sensitivity to Chemotherapy in Cancer Cells. Anticancer Agents Med Chem (2014) 14:18-28. doi: 10.2174/187152061401140108113435

155. Wang F, Meng F, Wong SCC, Cho WCS, Yang S, Chan LWC. Combination Therapy of Gefitinib and miR-30a-5p may Overcome Acquired Drug Resistance Through Regulating the PI3K/AKT Pathway in Non-Small Cell Lung Cancer. Ther Adv Respir Dis (2020) 14:1753466620915156. doi: $10.1177 / 1753466620915156$

156. Liang G, Zhu Y, Ali DJ, Tian T, Xu H, Si K, et al. Engineered Exosomes for Targeted Co-Delivery of miR-21 Inhibitor and Chemotherapeutics to Reverse Drug Resistance in Colon Cancer. J Nanobiotechnol (2020) 18:10. doi: 10.1186/s12951-019-0563-2

157. Xu X, Chen X, Xu M, Liu X, Pan B, Qin J, et al. miR-375-3p Suppresses Tumorigenesis and Partially Reverses Chemoresistance by Targeting YAP1 and SP1 in Colorectal Cancer Cells. Aging (Albany NY) (2019) 11:7357-85. doi: 10.18632/aging.102214

158. Xu F, Ye ML, Zhang YP, Li WJ, Li MT, Wang HZ, et al. MicroRNA-375-3p Enhances Chemosensitivity to 5-Fluorouracil by Targeting Thymidylate Synthase in Colorectal Cancer. Cancer Sci (2020) 111:1528-41. doi: $10.1111 /$ cas. 14356

159. Lai X, Eberhardt M, Schmitz U, Vera J. Systems Biology-Based Investigation of Cooperating microRNAs as Monotherapy or Adjuvant Therapy in Cancer. Nucleic Acids Res (2019) 47:7753-66. doi: 10.1093/nar/gkz638

160. Rupaimoole R, Han HD, Lopez-Berestein G, Sood AK. MicroRNA Therapeutics: Principles, Expectations, and Challenges. Chin J Cancer (2011) 30:368-70. doi: 10.5732/cjc.011.10186

Conflict of Interest: The authors declare that the research was conducted in the absence of any commercial or financial relationships that could be construed as a potential conflict of interest.

Publisher's Note: All claims expressed in this article are solely those of the authors and do not necessarily represent those of their affiliated organizations, or those of the publisher, the editors and the reviewers. Any product that may be evaluated in this article, or claim that may be made by its manufacturer, is not guaranteed or endorsed by the publisher.

Copyright (๑) 2021 Lahooti, Poudel, Mikelis and Mattheolabakis. This is an openaccess article distributed under the terms of the Creative Commons Attribution License (CC BY). The use, distribution or reproduction in other forums is permitted, provided the original author(s) and the copyright owner(s) are credited and that the original publication in this journal is cited, in accordance with accepted academic practice. No use, distribution or reproduction is permitted which does not comply with these terms. 